\title{
GMR
}

GlpC gene is responsible for biofilm formation and defense against phagocytes and imparts tolerance to $\mathrm{pH}$ and organic solvents in

\section{Proteus vulgaris}

\author{
Y.L. Wu, K.S. Liu, X.T. Yin and R.M. Fei \\ College of Veterinary Medicine, Nanjing Agricultural University, Nanjing, China \\ Corresponding author: R.M. Fei \\ E-mail: feirongmei@njau.edu.cn
}

Genet. Mol. Res. 14 (3): 10619-10629 (2015)

Received February 10, 2015

Accepted June 17, 2015

Published September 9, 2015

DOI http://dx.doi.org/10.4238/2015.September.9.3

\begin{abstract}
Biofilm-forming bacteria are highly resistant to antibiotics, host immune defenses, and other external conditions. The formation of biofilms plays a key role in colonization and infection. To explore the mechanism of biofilm formation, mutant strains of Proteus vulgaris $\mathrm{XC} 2$ were generated by $\mathrm{Tn} 5$ random transposon insertion. Only one biofilm defective bacterial species was identified from among 500 mutants. Inactivation of the $g l p C$ gene coding an anaerobic glycerol-3phosphate dehydrogenase subunit $C$ was identified by sequence analysis of the biofilm defective strain. Differences were detected in the growth phenotypes of the wild-type and mutant strains under $\mathrm{pH}$, antibiotic, and organic solvent stress conditions. Furthermore, we observed an increase in the phagocytosis of the biofilm defective strain by the mouse macrophage RAW264.7 cell line compared to the wild-type strain. This study shows that the $g l p \mathrm{C}$ gene plays an important role in biofilm formation, in addition to imparting $\mathrm{pH}$, organic solvent, and antibiotic tolerance, and defense against phagocytosis to Proteus sp. The results further clarified the mechanism of biofilm formation at the genomic
\end{abstract}


level, and indicated the importance of the $g l p C$ gene in this process. This data may provide innovative therapeutic measures against $P$. vulgaris infections; furthermore, as an important crocodile pathogen, this study also has important significance in the protection of Chinese alligators.

Key words: Biofilm; Chinese alligator; glpC; Proteus vulgaris

\section{INTRODUCTION}

Proteus vulgaris, an opportunistic pathogen found widely in nature, forms a part of the normal intestinal flora of many reptiles, birds, and mammals, including humans. P. vulgaris colonizes and causes diseases in these species through their virulence factors and ability to form biofilms. Many diseases caused by this pathogen have been reported; in addition, it has been recognized as major cross-infection pathogen in hospitals because of its strong adherence capacity and survival in so many intermediaries (Manos and Belas, 2006; Jacobsen and Shirtliff, 2011). More importantly, strains belonging to the Proteus sp. are often insensitive to the bactericidal action of normal human serum, which poses a clinical problem (Kwil et al., 2013).

Biofilm formation, which occurs under specific conditions, aids bacterial survival under many hostile conditions (Hall-Stoodley et al., 2004) and plays an important role in the persistence of infection (Costerton, 2001). One of the most intriguing and clinically relevant features of microbial biofilms is their significantly higher antibiotic resistance relative to their free-floating counterparts, which causes serious problems in the therapy of biofilm-associated infections. According to reports, the minimum inhibitory concentration (MIC) of antibiotics for biofilms can be 1000-fold higher than that for planktonic bacteria (Høiby et al., 2010). This warrants investigations of bacterial biofilms. Among the Proteus strains, the formation of biofilms by P. mirabilis on catheter material has been well-documented (Sabbuba et al., 2002; Liaw et al., 2003), although the gene responsible for biofilm development remains to be identified. Pratt and Kolter (1998) suggested that gene products that are important for biofilm development are also important for pathogenesis.

The Chinese alligator (Alligator sinensis), which is native to China, is a critically endangered species. In recent years, the number of Chinese alligators has increased markedly with the success of scale breeding. However, the number of Chinese alligators dying because of unknown reasons has also increased. The strain used in this study was isolated from a sick Chinese alligator at the Anhui Research Center of Chinese Alligator Reproduction. Evidence suggested that $P$. vulgaris was associated with the disease, although this was not confirmed. Proteus sp. associated with septicemia in crocodiles has been previously reported (Novak and Seigel, 1986). These observations highlight the threat posed to the health of Chinese alligators by Proteus sp. The aim of this study was to provide a reference for the prevention and treatment of Chinese alligators infected with this pathogen.

\section{MATERIAL AND METHODS}

\section{Strains, plasmids, and growth conditions}

The bacterial strains and plasmids used in this study are listed in Table 1. Both Escherichia coli and P. vulgaris strains were maintained in solid Luria-Bertani (LB) broth 
(containing $1.5 \%$ agar) or in liquid LB. In organic solvent tolerance assays, glucose $(0.1 \%)$ and $\mathrm{MgSO}_{4}(10 \mathrm{mM})$ were added to the LB medium (LBGMg medium). The RAW264.7 cell line was laboratory stored. Dulbecco's modified Eagle's medium-high glucose (DMEMHI) was obtained from HyClone (USA), fetal bovine serum (FBS) from Gibco (USA), and gentamicin (Gm; $100 \mu \mathrm{g} / \mathrm{mL}$ ), 24-well tissue culture plates, and 96-well tissue culture plates (Corning, USA). When required, antibiotics were added at the following concentrations: 100 $\mu \mathrm{g} / \mathrm{mL}$ ampicillin (Amp); $50 \mu \mathrm{g} / \mathrm{mL}$ kanamycin (Km); $25 \mu \mathrm{g} / \mathrm{mL}$ chloramphenicol (Cm); and $50 \mu \mathrm{g} / \mathrm{mL}$ polymyxin B. The antibiotics used here were purchased from Hangzhou Tianhe Microorganism Reagent Co. (China).

\begin{tabular}{|c|c|c|}
\hline Strains or plasmid & Description or/and relevant genotype & Source or reference \\
\hline \multicolumn{3}{|l|}{ Escherichia coli strains } \\
\hline S17-1 $\lambda$ pir & RP4-2-Tc::Mu aphA::Tn5recA pirlysogen & Laboratory stored \\
\hline SM10 $\lambda$ pir & $\mathrm{Km}^{\mathrm{r}}$, thi $i^{-1}, t h r$, leu, ton $\mathrm{A}$, lac $\mathrm{Y}, \sup \mathrm{E}, \operatorname{rec} \mathrm{A}:: \mathrm{RP} 4-2-\mathrm{Tc}:: \mathrm{Mu}, \lambda$ pir & Li et al., 2009 \\
\hline \multicolumn{3}{|l|}{ Proteus vulgaris strains } \\
\hline XC 2 & $A m p^{r}$ & Laboratory stored \\
\hline \multicolumn{3}{|l|}{ Plasmids } \\
\hline PUT mini-Tn5 Km1 & $\mathrm{Amp}^{\mathrm{r}}, \mathrm{Km}^{\mathrm{r}}$, ori $\mathrm{R}_{\mathrm{R}}$, ori $_{\mathrm{RP4}}$ & Li et al., 2009 \\
\hline PRK600 & $\mathrm{Cm}^{\mathrm{r}}$, triparental mating helper plasmid & Li et al., 2009 \\
\hline
\end{tabular}

\section{Triparental conjugation and selection of markerless recombinants}

Triparental conjugation was performed as described by Li et al. (2009) with some modifications. In brief, donor strains of E. coli S17-1 $\lambda$ pir, harboring the PUT mini-Tn5 vector, were mixed with helper strains of $E$. coli HB101 (pRK600) and recipient strains of $P$. vulgaris XC 2 at a ratio of 2:1:4. A $0.22-\mu$ m nylon membrane filter was placed on the surface of a LB plate, which was then spotted with the bacterial mix and incubated for $24 \mathrm{~h}$ at $37^{\circ} \mathrm{C}$. Cells on the filter surface were then suspended in sterile $\mathrm{H}_{2} \mathrm{O}$. Two-fold serial dilutions of the suspension were plated onto media containing antibiotics for counter-selection of donor strains, and selection of recipient cells carrying the transposon marker.

\section{Microtiter biomass assay}

The biofilm biomass of each mutant strain was determined as previously described (O'Toole and Kolter, 1998; Merritt et al., 2005; Jin et al., 2006) with some modifications. Overnight inoculum $(10 \mu \mathrm{L})$ was added to $200 \mu \mathrm{L}$ medium on each well of sterile 96 -well flat-bottomed polystyrene microplates, and then incubated at $37^{\circ} \mathrm{C}$ for $24 \mathrm{~h}$. The medium was removed and the wells were washed thrice with $200 \mu \mathrm{L}$ sterile PBS to remove planktonic bacteria. Absolute methanol $(200 \mu \mathrm{L})$ was added for $15 \mathrm{~min}$ to fix the attached bacteria. After drying, the wells were stained with $200 \mu \mathrm{L}(0.1 \%)$ crystal violet solution for $15 \mathrm{~min}$. Excess stain was removed by washing with tap water; the wells were then allowed to dry before the addition of $200 \mu \mathrm{L} \mathrm{95 \%} \mathrm{ethanol.} \mathrm{The} \mathrm{plates} \mathrm{were} \mathrm{shaken} \mathrm{gently} \mathrm{to} \mathrm{ensure} \mathrm{complete} \mathrm{dissolution}$ of the crystal violet and $\mathrm{OD}_{595}$ of each well was measured. Each strain was tested in triplicate; all tests were carried out thrice, and the average of the obtained results was determined. A wild-type strain (P. vulgaris XC 2) was used as a positive control, and the wells that had not been inoculated with bacteria were used as negative controls. 


\section{Determination of the insertion site}

The sequence of the insertion site of the mutant was obtained using thermal asymmetric interlaced PCR (TAIL-PCR) (Liu and Whittier, 1995). In this method, six specific primers and six degenerate primers were designed according to the transposon and bacterial genomic DNA sequences, respectively (Table 2). A third round of amplification was performed after the second amplification. Cycling conditions of TAIL-PCRs are listed in Table 3. Unpurified PCR products were directly used as the template for the next round of PCR after 20 dilutions (20X) with $\mathrm{ddH}_{2} \mathrm{O}$. The DNA fragments obtained after three sequential amplification steps were subjected to sequence analysis.

Table 2. Primers used in thermal asymmetric inter-laced polymerase chain reaction (TAIL-PCR).

\begin{tabular}{|c|c|c|}
\hline & Primer names & Sequences $\left(5^{\prime} \rightarrow 3^{\prime}\right)$ \\
\hline \multirow[t]{6}{*}{ Arbitrary degenerate primer (AD) } & AD1 & (G/C)TTGNTA(G/C)TNCTNTGC \\
\hline & AD2 & NTCGA(G/C)T(A/T)T(G/C)G(A/T)GTT \\
\hline & AD3 & (A/T)GTGNAG(A/T)ANCANAGA \\
\hline & AD4 & NGTCGA(G/C)(A/T)GANA(A/T)GAA \\
\hline & AD5 & TG(A/T)GNAG(G/C)ANCA(G/C)AGA \\
\hline & AD6 & AG(A/T)GNAG(A/T)ANCA(A/T)AGG \\
\hline \multirow[t]{3}{*}{ Upstream TAIL-PCR } & SP1 & CCGTGGCAAAGCAAAAGTTCAAAA \\
\hline & SP2 & GCAACACCTTCTTCACGAGGCAGA \\
\hline & SP3 & GCGCAGGGCTTTATTGATTCCATT \\
\hline \multirow[t]{3}{*}{ Downstream TAIL-PCR } & SP1 & ATCAACCGTGGCTCCCTCACTTTC \\
\hline & SP2 & GCCATCACGACTGTGCTGGTCATT \\
\hline & SP3 & GCCGGATCCTCTAGAGTCGACCTG \\
\hline
\end{tabular}

Primers SP1, SP2, and SP3 were used in the first, second, and third rounds of amplification, respectively. The intervals between SP1 and SP2, and that between SP2 and SP3 were approximately $100 \mathrm{bp}$; therefore, the target fragment was easily identifiable based on the $100 \mathrm{bp}$ differences between the three arbitrarily primed PCRs.

Table 3. Arbitrarily primed polymerase chain reaction (PCR) procedure.

\begin{tabular}{lccl}
\hline Reaction & Step & Cycle No. & Thermal condition \\
\hline First & 1 & 1 & $94^{\circ} \mathrm{C}(1 \mathrm{~min}), 98^{\circ} \mathrm{C}(1 \mathrm{~min})$ \\
& 2 & 5 & $94^{\circ} \mathrm{C}(30 \mathrm{~s}), 675^{\circ} \mathrm{C}(1 \mathrm{~min}), 72^{\circ} \mathrm{C}(2 \mathrm{~min})$ \\
& 3 & 1 & $94^{\circ} \mathrm{C}(30 \mathrm{~s}), 25^{\circ} \mathrm{C}(3 \mathrm{~min}), 72^{\circ} \mathrm{C}(2 \mathrm{~min})$ \\
& 4 & 15 & $94^{\circ} \mathrm{C}(30 \mathrm{~s}), 67.5^{\circ} \mathrm{C}(1 \mathrm{~min}), 72^{\circ} \mathrm{C}(2 \mathrm{~min})$ \\
& & & $94^{\circ} \mathrm{C}(30 \mathrm{~s}), 67.5^{\circ} \mathrm{C}(1 \mathrm{~min}), 72^{\circ} \mathrm{C}(2 \mathrm{~min})$ \\
Second & 5 & 1 & $94^{\circ} \mathrm{C}(30 \mathrm{~s}), 44^{\circ} \mathrm{C}(1 \mathrm{~min}), 72^{\circ} \mathrm{C}(2 \mathrm{~min})$ \\
& 6 & 15 & $72^{\circ} \mathrm{C}(10 \mathrm{~min})$ \\
& & & $94^{\circ} \mathrm{C}(30 \mathrm{~s}), 65^{\circ} \mathrm{C}(1 \mathrm{~min}), 72^{\circ} \mathrm{C}(2 \mathrm{~min})$ \\
Third & 7 & 1 & $94^{\circ} \mathrm{C}(30 \mathrm{~s}), 65^{\circ} \mathrm{C}(1 \mathrm{~min}), 72^{\circ} \mathrm{C}(2 \mathrm{~min})$ \\
& 8 & 15 & $94^{\circ} \mathrm{C}(30 \mathrm{~s}), 44^{\circ} \mathrm{C}(1 \mathrm{~min}), 72^{\circ} \mathrm{C}(2 \mathrm{~min})$ \\
& & & $72^{\circ} \mathrm{C}(10 \mathrm{~min})$ \\
& 9 & $94^{\circ} \mathrm{C}(30 \mathrm{~s}), 67.5^{\circ} \mathrm{C}(1 \mathrm{~min}), 72^{\circ} \mathrm{C}(2 \mathrm{~min})$ \\
\hline
\end{tabular}

After the first reaction, the unpurified products were diluted (20X) with $\mathrm{ddH}_{2} \mathrm{O}$ and used as the template in the second reaction; this process was repeated for the third reaction.

\section{Minimal inhibitory concentration (MIC) assay for planktonic and biofilm cells}

The MICs of gentamicin and chloramphenicol for planktonic and biofilm cells of the wild-type and mutant strains were determined using microtiter plate assays, as described 
previously (Asako et al., 1997; Steinberg et al., 1997; Kavanaugh and Ribbeck, 2012) with some modifications. Antibiotics were diluted in growth medium and $200 \mu \mathrm{L}$ of this was added to $10 \mu \mathrm{L}$ bacteria on each well of the 96-well plate. Biofilm cells were cultured as previously described. Planktonic cells were washed with sterile PBS before the addition of $200 \mu \mathrm{L}$ growth medium containing diluted antibiotics. The $\mathrm{OD}_{600}$ of each well was measured after incubation at $37^{\circ} \mathrm{C}$ for $16 \mathrm{~h}$. Bacteria cultured in medium without antibiotics and medium alone were used as controls.

\section{Different pH growth conditions}

The $\mathrm{pH}$ of $\mathrm{LB}$ was adjusted to 5.0, 6.0, 7.0, 8.0, and 9.0 using $1 \mathrm{M} \mathrm{HCl}$ or $1 \mathrm{M} \mathrm{NaOH}$. The growth curve of bacteria under suboptimal $\mathrm{pH}$ conditions was obtained as described by Markkula et al. (2012) and Mangold et al. (2013). Prior to the experiment, LB broth containing the appropriate antibiotics was inoculated with the bacterial strains cultured on blood agar plates. Bacteria were cultured until an $\mathrm{OD}_{600}$ of 0.4-0.6 was reached. The $\mathrm{OD}_{600}$ of $50 \mathrm{~mL}$ fresh LB medium adjusted to different $\mathrm{pH}$ values was adjusted to 0.02 after inoculation with the bacterial cultures, and incubated at $37^{\circ} \mathrm{C}$ with shaking $(180 \mathrm{rpm})$. The $\mathrm{OD}_{600}$ was monitored every hour for $16 \mathrm{~h}$.

\section{Organic solvent tolerance assay}

In the organic solvent tolerance assays, bacteria were cultured in LBGMg according to the method described by Asako (1997). Overnight cultures $(100 \mu \mathrm{L})$ of the wild-type and mutant strains were inoculated in $5 \mathrm{~mL}$ of fresh $\mathrm{LBGMg}$ medium and incubated at $37^{\circ} \mathrm{C}$ with shaking (180 rpm). The culture was overlaid with a $10 \%$ volume of cyclohexane or $n$-hexane during the early exponential phase of growth. $\mathrm{OD}_{600}$ was measured at 16 and $24 \mathrm{~h}$.

\section{Phagocytosis assays}

Phagocytosis assays of $P$. vulgaris $\mathrm{XC} 2$ and the mutant strain were performed as described previously (Valentin-Weigand et al., 1996; Segura et al., 1998; Chen et al., 2008) with some modifications. Bacterial suspensions $\left(5 \times 10^{5} \mathrm{CFU} / \mathrm{mL}\right)$ were prepared in DMEM supplemented with $2 \%$ FBS. Monolayers of RAW264.7 cells (approximately $5 \times 10^{5}$ cells per well) were plated on 24-well tissue culture plates. After washing twice with warm PBS, $1 \mathrm{~mL}$ of the bacterial suspension was added to the cell monolayers, and incubated at $37^{\circ} \mathrm{C}$ in a humidified 5\% $\mathrm{CO}_{2}$ incubator for $1 \mathrm{~h}$. After incubation, the cells were washed twice with warm PBS (again), and incubated for a further $1 \mathrm{~h}$ with medium containing gentamicin (100 $\mu \mathrm{g} / \mathrm{mL}$ ) to kill the extracellular bacteria. The cell monolayers were then washed twice with warm PBS and $1 \mathrm{~mL}$ of sterile distilled water was added to every well to lyse the cells. The numbers of intracellular bacteria were confirmed by quantitative plating of serial 10-fold dilutions on LB agar. For spot assays (Yu et al., 2012; Holdsworth and Law, 2013), aliquots $(10 \mu \mathrm{L})$ of cell lysates of every dilution were spotted onto LB plates, in order to estimate the numbers of viable wild-type strain $P$. vulgaris XC 2 and mutant strain bacteria phagocytized by RAW264.7 cells. Each strain was tested in triplicate; all tests were performed thrice and the average of the results obtained was determined. Bacteria in the absence of RAW264.7 cells and cell monolayers without bacteria were set up as controls. 


\section{Statistical analysis}

Each test was performed at least in triplicate, and results are reported as means \pm standard error (SE). Differences were analyzed for significance using the Student $t$-test. P values less than 0.05 were considered to be statistically significant.

\section{RESULTS}

\section{Triparental conjugation and selection of markerless recombinants and microtiter biomass assay}

Approximately 500 transposon mutants were obtained. In the subsequent biofilm detection, each strain was tested in triplicate and the average of the results of three tests was obtained. A mutant strain $\left(\mathrm{OD}_{595}: 0.5550 \pm 0.0883\right)$ exhibiting significantly different biomass compared to $P$. vulgaris $\mathrm{XC} 2\left(\mathrm{OD}_{595}: 1.4361 \pm 0.1646\right)$ was obtained $(* * \mathrm{P}<0.01)$. This mutant strain was used in further studies.

\section{Thermal asymmetric interlaced PCR and sequencing}

The DNA sequence flanking the insertion elements was determined in order to identify the disrupted gene. Thermal asymmetric interlaced PCR method was used to amplify the target DNA fragment, which was purified for sequencing after the third round of PCR. Approximately $580 \mathrm{bp}$ of DNA sequence located in the upstream region of the transposon insertion of the mutant strain was obtained. Homologous nucleotide sequences were searched for in the National Center for Biotechnology Information (NCBI) database (http://www.ncbi. nlm.nih.gov/). The 580-bp DNA fragment obtained was found to exhibit $84 \%$ homology with the $g l p \mathrm{C}$ and $g l p \mathrm{~B}$ genes of $P$. mirabilis (the genome of $P$. vulgaris remains unpublished to date) and the insertion element of the mutant was located in the $g l p C$ gene, encoding subunit $\mathrm{C}$ of $s n$-glycerol-3-phosphate dehydrogenase.

\section{Analysis of antibiotic sensitivity}

The degree of chloromycetin and gentamicin sensitivity of planktonic and biofilm cells was analyzed by the MIC assay (Table 4). Though the biofilm cells and planktonic cells of two strains showed a similar MIC as that of gentamicin, we observed a difference in the MIC to chloromycetin, that is, the MIC of biofilm cells of $P$. vulgaris XC 2 was greater than that of the planktonic and biofilm cells of the mutant strain P. vulgaris XC 2.

\begin{tabular}{|c|c|c|c|c|}
\hline \multirow[t]{2}{*}{ Bacteria } & \multicolumn{2}{|c|}{ Proteus vulgaris XC 2} & \multicolumn{2}{|c|}{ Mutant strain } \\
\hline & Biofilm & Planktonic & Biofilm & Planktonic \\
\hline Chloromycetin & 100 & 12.5 & 12.5 & 6.25 \\
\hline Gentamicin & 25 & 12.5 & 12.5 & 12.5 \\
\hline
\end{tabular}




\section{Bacterial growth under varying $\mathrm{pH}$ conditions}

P. vulgaris XC 2 and mutant strain were cultured in LB adjusted to $\mathrm{pH}$ 5.0, 6.0, 7.0, 8.0, and 9.0. Growth was monitored by measurement of $\mathrm{OD}_{600}$ at $1 \mathrm{~h}$ intervals for $16 \mathrm{~h}$ (Figure 1). The two strains exhibited similar growth at $\mathrm{pH}$ values of 6.0, 7.0, and 8.0, reaching a stationary phase at approximately the same time. The growth of the mutant strain was slightly better than that of the wild-type cells once the stationary phase was reached (Figure 1A, B, C, $\mathrm{D}$ ); however, the phenomenon was revised at $\mathrm{pH}$ 5.0. As the $\mathrm{pH}$ increased to 9.0, the lag phase of $P$. vulgaris $\mathrm{XC} 2$ growth was greatly increased, while the growth of the mutant strain was inhibited, compared to $P$. vulgaris XC 2.
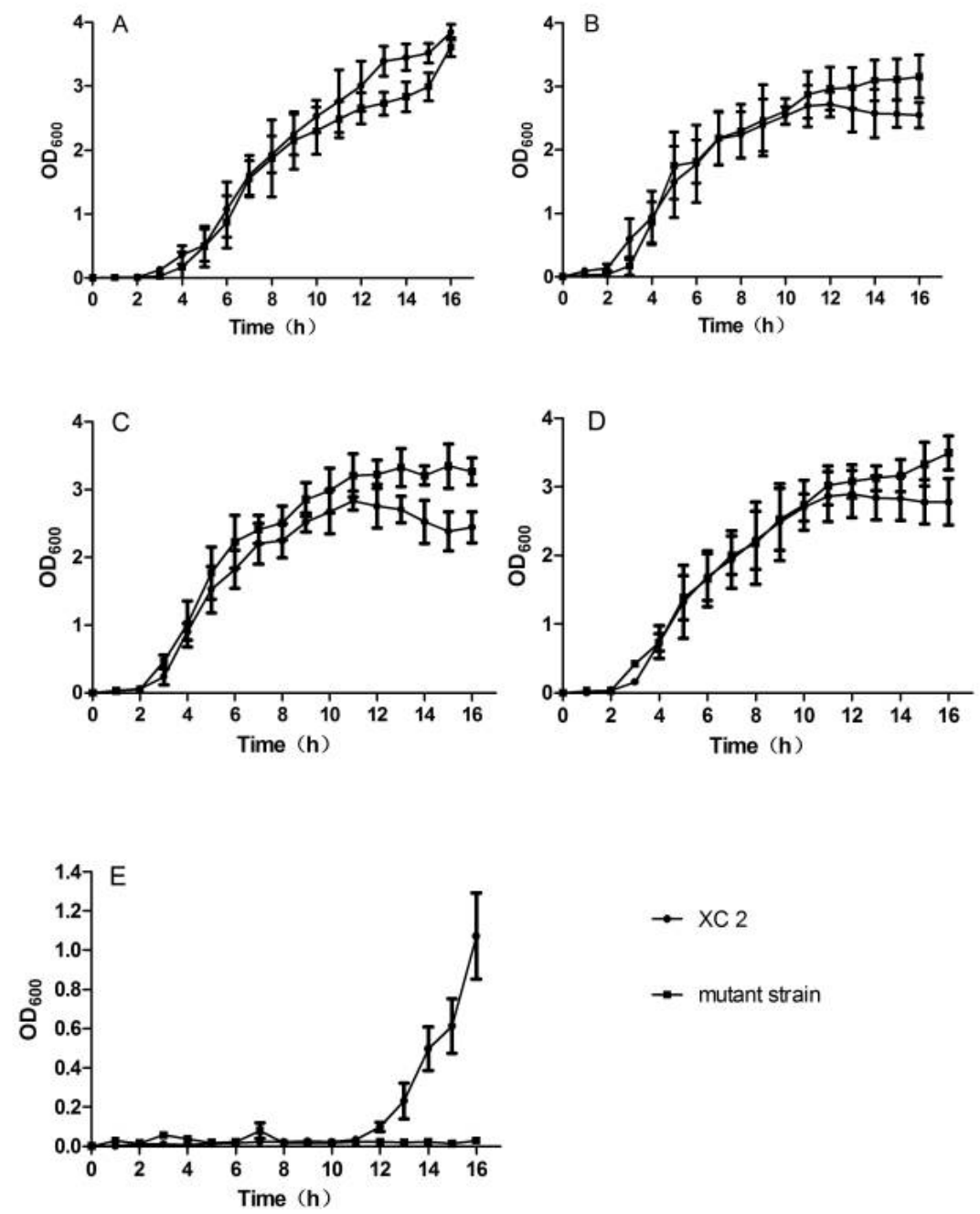

Figure 1. Growth curve of Proteus vulgaris XC 2 (XC 2) and mutant strain under different $\mathrm{pH}$ conditions. (A) $\mathrm{pH}$ $5.0,37^{\circ} \mathrm{C}$; (B) $\mathrm{pH} 6.0,37^{\circ} \mathrm{C} ;(\mathbf{C}) \mathrm{pH} 7.0,37^{\circ} \mathrm{C}$; (D) $\mathrm{pH} 8.0,37^{\circ} \mathrm{C}$; (E) $\mathrm{pH} 9.0,37^{\circ} \mathrm{C}$. Results are reported as means \pm standard error (SE). 


\section{GlpC is responsible for organic solvent tolerance}

The $\mathrm{OD}_{600}$ values of $P$. vulgaris XC 2 and the mutant strain were measured at 16 and 24 $\mathrm{h}$ (Figure 2). The growth of the wild-type and mutant strains was inhibited at varying degrees when cultured in the presence of different organic solvents. P. vulgaris XC 2 and the mutant strain showed similar tolerance to the organic solvents at $16 \mathrm{~h}$. Following continued culturing up to $24 \mathrm{~h}$, the $\mathrm{OD}_{600}$ of P. vulgaris XC 2 was found to be apparently greater than that of the mutant strain in media containing cyclohexane $(* * \mathrm{P}<0.01)$, although there was no significant difference in the growth curves of the two strains cultured in media containing $n$-hexane.
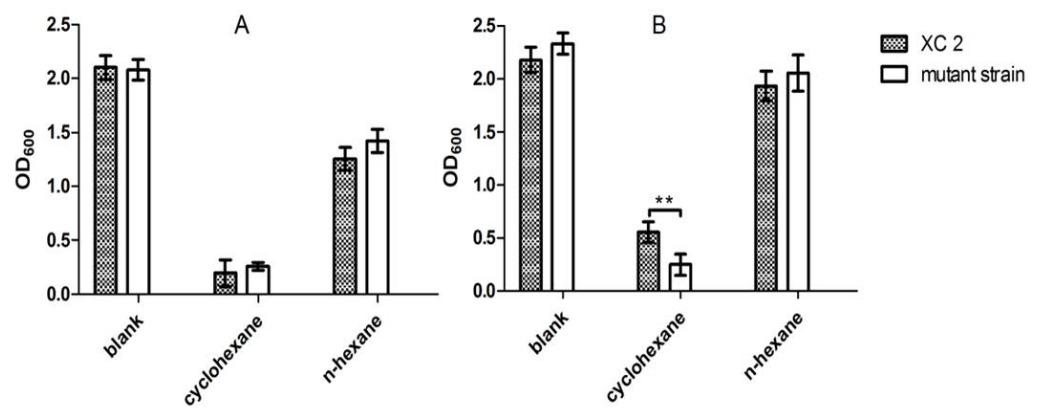

Figure 2. Organic solvent susceptibility of Proteus vulgaris XC 2 (XC 2) and mutant strain. $\mathrm{OD}_{600}$ values at (A) $16 \mathrm{~h}$ and (B) $24 \mathrm{~h}$ are shown. The group without any organic solvent was used as a control (blank). Results are reported as means $\pm \mathrm{SE}$.

\section{Phagocytosis assays}

Phagocytosis of the two strains was analyzed by measuring the number of viable intracellular bacteria after incubation with RAW264.7 cells. The percentage of $P$. vulgaris XC 2 and mutant strains phagocytized was calculated using the equation reported by Chen (2008). Phagocytosis of the mutant strain by RAW264.7 was more than 2.5-fold greater than that of P. vulgaris $\mathrm{XC} 2(31.7 \pm 5.7$ vs $13.0 \pm 0.76 \%$, respectively; $* \mathrm{P}<0.05)$ (Figure $3 \mathrm{~A})$. This trend was also observed in the spot assay (Figure 3B).

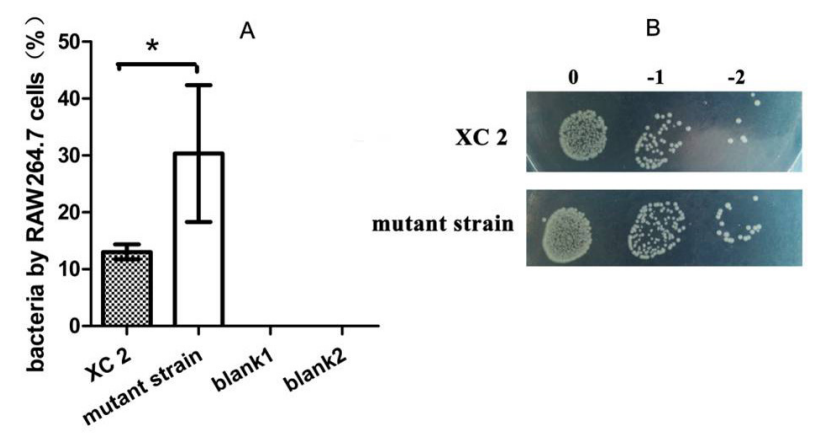

Figure 3. Phagocytosis assays. (A) Phagocytic uptake of Proteus vulgaris XC 2 (XC 2) and the mutant strain by RAW264.7 cells $(* \mathrm{P}<0.05)$. Blank 1: P. vulgaris XC 2 without RAW264.7 cells $(0.020 \pm 0.0046 \%)$; blank 2 : mutant strain without RAW264.7 cells $(0.017 \pm 0.0015 \%)$. (B) A serial dilution assay was performed to evaluate the number of viable bacteria. Dilutions of the bacteria $\left(10^{0}, 10^{-1}\right.$, and $\left.10^{-2}\right)$ were spotted $(10 \mu \mathrm{L})$ onto the plate. Results are reported as means $\pm \mathrm{SE}$. 


\section{DISCUSSION}

In this study, we observed an evident decrease in the biofilm-forming ability of the mutant strain obtained by random transposon insertion mutation, with the $\mathrm{OD}_{595}$ value (measured in biomass assays) reduced by more than 50\%. Thermal asymmetric interlaced PCR was used to determine the insertion site using six arbitrary degenerate primers, in order to increase the achievement ratio. Furthermore, three rounds of amplification were conducted to enrich the flanking DNA. Finally, the $g l p C$ gene was identified as the insertion site in the obtained biofilm defective strain. In E. coli, glpC has been demonstrated to play an important role in increasing the organic solvent tolerance, through analysis of gene expression profiles before and after exposure to organic solvents (Shimizu et al., 2005).

The biofilm cells of $P$. vulgaris XC 2 demonstrated significantly greater resistance to chloromycetin than planktonic cells. In this study, the tolerance of biofilm cells of $P$. vulgaris $\mathrm{XC} 2$ to chloromycetin was greater than that to gentamicin. This was speculated to be a result of differences in the penetration of biofilm by the two antibiotics, and/or differences in the mechanisms by which the antibiotics function.

Maintenance of a circumneutral intracellular $\mathrm{pH}$ is important for any organism (Mangold et al., 2013). According to Finlay and Falkow (1997) and Hoyle and Costerton (1991), biofilms are complex aggregations of planktonic microorganisms. It is not clear whether the aggregations were related to the large $\mathrm{OD}_{600}$ of the biofilm defective strain at $\mathrm{pH}$ 6.0, 7.0, and 8.0. The growth of $P$. vulgaris XC 2 was increased compared to that of the mutant strain, as the $\mathrm{pH}$ of the culture medium was reduced from 7.0 to 5.0, demonstrating the greater tolerance of $P$. vulgaris XC 2 to the acidic environment. Growth of the mutant strain within 16 $\mathrm{h}$ was negligible at $\mathrm{pH} 9.0$; however, at $24 \mathrm{~h}$, the $\mathrm{OD}_{600}$ value of the mutant strain reached 0.41 (data not shown). These observations demonstrated the greater tolerance of $P$. vulgaris $\mathrm{XC} 2$ to alkaline environments compared to the mutant strain, thereby indicating the importance of $g l p \mathrm{C}$ in $\mathrm{pH}$ tolerance.

Organic solvents are toxic to most microorganisms (Ni et al., 2013). In this study, the effects of inactivation of the $g l p \mathrm{C}$ gene in $P$. vulgaris yielded similar results to those obtained by Shimizu (2005). The sensitivity of the mutant strain to $n$-hexane stress was unchanged compared to that of the wild-type strain. However, in response to cychlohexane stress, the growth of both strains was evidently inhibited over the first $16 \mathrm{~h}$ of culture. With prolonged culture under these conditions, the greater tolerance of wild-type strain became more apparent. Therefore, it can be hypothesized that $g l p C$ does not function under $n$-hexane tolerance, or that the tolerance of $P$. vulgaris to $n$-hexane is achieved by simultaneous changes in the expression of many related genes. Furthermore, the role of $g l p C$ in cychlohexane tolerance was clearly demonstrated with continued culture, indicating that other relevant genes may be activated. The biomass of P. vulgaris XC 2 was also measured at different times (data not shown); this showed that the biofilm formation was not completed during the early stages of culture. However, biofilm formation was found to be accelerated after $16 \mathrm{~h}$, with the gradual formation of a mature biofilm. This might explain the differences in the growth of P. vulgaris XC 2 and the mutant strain, in media containing cychlohexane. Therefore, the relationship between biofilm formation and organic solvent tolerance should be further investigated.

In view of the role of biofilms in bacterial escape from the host immune system (Pearson et al., 1997), the interactions of $P$. vulgaris XC 2 and the biofilm defective strain 
with mouse macrophage RAW262.7 cells were studied. Phagocytosis of the mutant strain by RAW264.7 cells was significantly greater than that of the wild-type strain, indicating that $g l p C$ plays an important role in bacterial resistance to phagocytosis by RAW264.7 cells. However, it is not clear whether this effect is caused directly by the disruption of $g l p C$ or indirectly by the decrease in biofilm formation.

The detailed mechanism of biofilm formation and the relationship between biofilms and tolerance to changes in $\mathrm{pH}$ and organic solvent stress require further investigation. Differential gene and protein expression analyses will provide important insights into the mechanisms underlying these effects, and provide the basis for the development of novel approaches for the protection and treatment of this pathogen in Chinese alligators (Novak and Seigel, 1986).

\section{Conflicts of interest}

The authors declare no conflict of interest.

\section{ACKNOWLEDGMENTS}

We are grateful to the Laboratory of Microbiology in College of Veterinary Medicine, Nanjing Agricultural University for providing the experimental equipment. Research supported by grants from the Special Fund for State Forestry Administration, and the Priority Academic Program Development of Jiangsu Higher Education Institutions.

\section{REFERENCES}

Asako H, Nakajima H, Kobayashi K, Kobayashi M, et al. (1997). Organic solvent tolerance and antibiotic resistance increased by overexpression of marA in Escherichia coli. Appl. Environ. Microbiol. 63: 1428-1433.

Chen PM, Chen HC, Ho CT, Jung CJ, et al. (2008). The two-component system ScnRK of Streptococcus mutans affects hydrogen peroxide resistance and murine macrophage killing. Microbes Infect. 10: 293-301.

Costerton JW (2001). Cystic fibrosis pathogenesis and the role of biofilms in persistent infection. Trends Microbiol. 9: $50-52$.

Finlay BB and Falkow S (1997). Common themes in microbial pathogenicity revisited. Microbiol. Mol. Biol. Rev. 61: 136-169.

Hall-Stoodley L, Costerton JW and Stoodley P (2004). Bacterial biofilms: from the natural environment to infectious diseases. Nat. Rev. Microbiol. 2: 95-108.

Høiby N, Bjarnsholt T, Givskov M, Molin S, et al. (2010). Antibiotic resistance of bacterial biofilms. Int. J. Antimicrob. Agents 35: 322-332.

Holdsworth SR and Law CJ (2013). Multidrug resistance protein MdtM adds to the repertoire of antiporters involved in alkaline pH homeostasis in Escherichia coli. BMC Microbiol. 13: 113.

Hoyle BD and Costerton JW (1991). Bacterial resistance to antibiotics: the role of biofilms. Prog. Drug Res. 37: 91-105.

Jacobsen SM and Shirtliff ME (2011). Proteus mirabilis biofilms and catheter-associated urinary tract infections. Virulence 2: 460-465.

Jin H, Zhou R, Kang M, Luo R, et al. (2006). Biofilm formation by field isolates and reference strains of Haemophilus parasuis. Vet. Microbiol. 118: 117-123.

Kavanaugh NL and Ribbeck K (2012). Selected antimicrobial essential oils eradicate Pseudomonas spp. and Staphylococcus aureus biofilms. Appl. Environ. Microbiol. 78: 4057-4061.

Kwil I, Kaźmierczak D and Różalski A (2013). Swarming growth and resistance of Proteus penneri and Proteus vulgaris strains to normal human serum. Adv. Clin. Exp. Med. 22: 165-175.

Li R, Wang G, Shen B, Wang R, et al. (2009). Random transposon vectors pUTTns for the markerless integration of exogenous genes into Gram-negative eubacteria chromosomes. J. Microbiol. Methods 79: 220-226.

Liaw SJ, Lai HC, Ho SW, Luh KT, et al. (2003). Role of RsmA in the regulation of swarming motility and virulence factor 
expression in Proteus mirabilis. J. Med. Microbiol. 52: 19-28.

Liu YG and Whittier RF (1995). Thermal asymmetric interlaced PCR: automatable amplification and sequencing of insert end fragments from PI and YAC clones for chromosome walking. Genomics 25: 674-681.

Mangold S, Rao JV and Dopson M (2013). Response of Acidithiobacillus caldus toward suboptimal pH conditions. Extremophiles 17: 689-696.

Manos J and Belas R (2006). The genera Proteus, Providencia and Morganella. Prokaryotes 6: 245-269.

Markkula M, Mattila M, Lindström M and Korkeala H (2012). Genes encoding putative DEAD-box RNA helicases in Listeria monocytogenes EGD-e are needed for growth and motility at $3^{\circ} \mathrm{C}$. Environ. Microbiol. 14: 2223-2232.

Merritt JH, Kadouri DE and O'Toole GA (2005). Growing and analyzing static biofilms. Curr. Prot. Microbiol. 1B-1.

Ni Y, Song L, Qian XH and Sun ZH (2013). Proteomic analysis of Pseudomonas putida reveals an organic solvent tolerance-related gene mmsB. PLoS One 8: e55858.

Novak SS and Seigel RA (1986). Gram-negtive septicemia in American alligators (Alligator mississippiensis). J. Wildl. Dis. 22: 484-487.

O’Toole GA and Kolter R (1998). Initiation of biofilm formation in Pseudomonas fluorescens WCS365 proceeds via multiple, convergent signaling pathways: a genetic analysis. Mol. Microbiol. 28: 449-461.

Pearson JP, Pesci EC and Iglewski BH (1997). Roles of Pseudomonas aeruginosa las and rhl quorum-sensing systems in control of elastase and rhamnolipid biosynthesis genes. J. Bacteriol. 179: 5756-5767.

Pratt LA and Kolter R (1998). Genetic analysis of Escherichia coli biofilm formation: roles of flagella, motility, chemotaxis and type I pili. Mol. Microbiol. 30: 285-293.

Sabbuba N, Hughes G and Stickler DJ (2002). The migration of Proteus mirabilis and other urinary tract pathogens over Foley catheters. BJU Int. 89: 55-60.

Segura MA, Cléroux P and Gottschalk M (1998). Streptococcus suis and group B Streptococcus differ in their interactions with murine macrophages. FEMS Immunol. Med. Microbiol. 21: 189-195.

Shimizu K, Hayashi S, Kako T, Suzuki M, et al. (2005). Discovery of glpC, an organic solvent tolerance-related gene in Escherichia coli, using gene expression profiles from DNA microarrays. Appl. Environ. Microbiol. 71: 1093-1096.

Steinberg DA, Hurst MA, Fujii CA, Kung AH, et al. (1997). Protegrin-1: a broad-spectrum, rapidly microbicidal peptide with in vivo activity. Antimicrob. Agents Ch. 41: 1738-1742.

Valentin-Weigand P, Benkel P, Rohde M and Chhatwal GS (1996). Entry and intracellular survival of group B streptococci in J774 macrophages. Infect. Immun. 64: 2467-2473.

Yu KO, Jung J, Ramzi AB, Choe HH, et al. (2012). Increased ethanol production from glycerol by Saccharomyces cerevisiae strains with enhanced stress tolerance from the overexpression of SAGA complex components. Enzyme Microb. Technol. 51: 237-243. 